\section{ON THE TREATMENT OF ANEURISM BY COMPRESSION.}

TO THE EDITOR OF THE PROVINCIALMEDICAL AND GURGICAL JOURNAL.

\section{Sir,}

As the treatment of aneurism by compression is now exciting surgical attention, perhaps you may think the following case, which bears upon it, not unworthy of record.

Some years ago I was present when a young man punctured the brachial artery, in bleeding at the bend of the arm. An abundant pulsatory stream of arterial blood showed that the opening into the artery was not a very small one; while from the large escape of venous blood it was plain that the vein had been transfixed. I loosened the bandage while pressure was applied to the wound, and placing a tourniquet over the brachial artery, about the middle of the shaft of the humerus, intended to apply a ligature above and below the wound; but venous blood welled out so abundantly, that it was clear that fainting would ensue if not speedily checked. Under these circumstances, finding the agitated young man was unable to keep up effectual pressure on the veins, whilst I shoild' 'operate, I applied a tourniquet over them, two or three inches beiow the wound. The hrmorrhage was now effectually stopped, and I proceeded to cut down on the artery. All the tissues were, however, so injected with blood, that I found it scarcely possible to discriminate one from the other, especially as I dreaded to cut through the bicipital fascia, and consequently was working in a confined space.

In this way from thirty to forty minutes had elapsed before I came to what I believed to be the artery. I loosened the screw of the upper tourniquet, and finally removed all pressure, but there was no pulsation, neither was there any hæmorrbage. The tourniquet was reapplied, and I again searched for the artery. At length I tied something, (but I feel persuaded that it was not the artery,) and then loosened both tourniquets, and finally removed them. No hsemorrhage took place either from vein or artery; the lips of the wound were brought together, and adhesive straps, and a gentle bandage completed the dressing; the arm was put in a sling; a fortnight afterwards the wound was healed. I saw the patient six months after, when no pulsation could be felt at the bend of the arm, and the pulse at the wrist was weaker tlian in the left arm; he said the arm was as strong as ever.

The patient was a strong muscular man, about 45 years of age. About a quart of blood was lost befure the second tourniquet was applied; he was pullid, but did not faint; he had had some injury to the right hand, which required the use of the sling for some weeks after the wound in the bend of the arm was healed.

This case would staggest inany reflections. It seems evident that the stagnation of the blood in the wounded artery and vein, for a distance of six or eight inches, was followed by its firm coagulation, which resisted the impulse of the circulation when the tourniquets were removed. I aun persuaded the artery was not included in the ligature; first, from the small size of the included vessel; secondly, from the absence of the peculiar sensation on tightening the ligature on an artery, (as if it were cutting bluntly through the coats); and, thirdly; from the apparent course of the vessel downwards, superficial to the muscles. It was probably a deeply seated vein. It certainly was not the wounded rein.

Admitting then that this was simply a case of wounded artery, treated by firm pressiure above and below the' wound, continued for less than an hour, the force of the circulation having been previously weakened by the abstraction of blood to approaching deliquium, I think the result is very encouraging. Would it not be advisable in every case of wounded artery at the bend of the arm, to try these simple n:eans first, instead of pressure applied over the wound itself, as recommended by $\mathrm{Mr}$. Liston? And may we not thus avoid a very difficult and painful operation, one too which usually involves the incision of the bicipital fascia, and a consequent permanent weakening of the arm ? May not this plan of treatment be applied to aneurisms also?

What was the influence of the loss of so large a quantity of blood previous to the application of pressure,-how much was owing to the alarm and fears of the patient, (by no means a timid subject, however,)and what was due to the length of time which the arm was allowed to rest, in consequence of an infiamed state of the hand, I feel myself incompetent to decide.

$$
\begin{aligned}
& \text { I am, Sir, } \\
& \text { Your obedient servant, }
\end{aligned}
$$

\section{F. NESBITT}

Yeovil, Sept. 6, 1845.

\section{ON PERFORATING ULCERATION OF THE STOMACH.}

TO THE EDITOR OF THE PROVINCIAL MLDICAL AND SURGICAL JOURNAL.

Sir,

I have read with much interest the three cases of perforation of the stomach, very recently recorded in your Journal, by Messrs. Young, Collyns, and Cox. It will be seen that the putients were all females, under 21 years of age. Mr. Cox says, "since the publication of Dr. Young's case, I do not think the mere circumstance of youth in my patient so reınarkable as I previously did."

Huving paid much attention to this lesion, (simple ulceration of the stomach,) I am induced to send you the conclusions I came to in a paper published in the Lancet, August 5th, 1843, believing that they will not be uninteresting to your readers. From subsequent experience I am induced to adhere to the opinion I formed unany years since, viz., that uterine derangement is, in the majority of cases, the predisposing cause of this affection.

$$
\begin{aligned}
& \text { I ain, Sir, } \\
& \text { Your obedient servant, }
\end{aligned}
$$
EDWARDS CRISP.

Walworth, September 5, 1845.

DEDUCTIÓNS.

Cases., , 51$\}$ Females . . . . 39 
The ages of the females were as follows:-

Between 15 and 20 . . . . . . 21

" 20 " 25 . . . . . . . 10

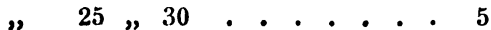

" 30 " 40 . . . . . . . 1

" 40,50 . . . . . . . 1

" 50 " 60 . . . . . . . 1

Previous state of health.-The greater number suffered from dyspeptic symptoms prior to the attack; the most frequent of which were occasional pain in the region of the stomach and left side, pyrosis, and flatulence. Vomiting was not a constant symptom, although it occurred in many instances. The menses were irregular in thirteen; in twenty-five this function is not mentioned; in one only the patient menstruated a month before the attack.

Most, (if not all,) of the females, uere unmarried.

Duration of the attack from twelve to thirty hours. In one instance, (Dr. Elliotson's patient,) life was prolonged for seventy hours.

Murbid Appearances. - The apertures in the majority of the cases were situated in the smaller curvature, more frequently midway between the pyloric and cardiac openings, but in many instances near the cardia. In one case only, was the perforation close to the pylorus, and in this instance it will be seen that a fibrous tubercular excrescence existed externally. In nine examples, as in Mr. Cox's case, two ulcers were present, opposite to each other, so that when the stomach was in a state of collapse, the diseased parts were in contact.

Males.-Ot these only one was under twenty years of age. The aperture in nine was close to the pylorus; in three midway between the openings.* Five of the examples were of a doubtful character, the parts around the opening being hard and callous.

- I betieve examples of simple ulceration in the cardiac eztremity of the stomacb in the male are very rare. The case of the celebrated chemist, Bechard, is, however, often quoted as an instance of this kind. The ulcer in his case is supposed to have cicatrized.

\section{REMARKS UPON MR. JACKSON'S CASE OF GASTRO'TUMY.}

TO THE KDITOR OF THE PROVINCIAL MEDICAI, AND SURGICAL JOURNAL.

Sir,

I have read with much interest Mr. Jackson's case of gastrotomy, reported in your Jomrnal for the 3rd inst., and quite accord in his view of the propriety of the operation in such an instance of ruptured uterus as that he describes; but $I$ an desirous of drawing his attention, and that of your readers, to a point in the after-treatment, where I think the practice of very questionable propriety.

The operation of gastrotoiny, in consequence of ruptured uterus, w:is performed on the 19th of November. On the following day pills, containing one grain of opium, and two grains of calomel, were directed to be given every four or six hours. In the evening of the same day the pills were ordered to be continued; on the next day, 21st, the same pills were prescribed, "when pain or restlessness were urgent," but whether the dose was given more or less frequently, does not appear. In the evening of this day, the calomel and opium, the latter in larger quantity, were "persisted in."

On the 22nd, Mi. Jackson describes the case as one presenting "two terrific irjuries, rupture of the uterus, and the external wound," and he properly remarks, that "the business of the juticious prac. titioner was to steer his course with great circumspection ; to do enough, but not ton much." "The large quantity of blood lost," he further observes, "tended to give the case, in its general features, the character of diminished or exhazsted power," but still the calomel and opium were administered conditionally, in reference to pain, uneasiness, or restlessness.

On the 23rd, "it became evident that the powers were nearly at their lowest ebb," when the calomel was suspended, the opium being continued, according to the degree of pain and restlessness. The conclusion of the report is, that the patient "finally sank on the eighth day after delivery. It is probable that the calomel had slightly affected the moutll about the fifth or sixth day."

'The question I would raise in reference to the aftertreaturentief this important case is, Was the adıninistration of calomel indicated? In my view, with two such formidable injuries as existed, and with such weakened powers of constitution, the great object should have been solely to support the strength, and aid the powers of nature in repairing the extensive lesions. Now the constitutional action of mercury seems to me particularly calculated to interfere with and retard these purposes.

It does rot appear how much calomel the patient took, but it is probable that, during the three days it was prescribed, she did not take fewer than nine or ten doses, say eighteen graius. Now I cannot think it safe to give a patient, in such circumstances as those described, so large a quantity of calomel. Having been in practice for thirty years, and by no means afraid of prescribing calomel, even in large doses, where the cases have appeared clearly to demand the remedy, I should cautiously have avoiled giving a single grain in such a case as Mr. Jackson's. I cannot conceive in what way it could aid in the healing of two such formidable wounds as existed, or how it could do otherwise than tend to depress and debilitate a constitution so much in need of strength and support.

I make these remarks with the most friendly feeling. I may be wrong in my views, but I an satisfied that calomel is often administered in a most inconsiderate manner ; and I believe that, in elderly people especially, labouring under bronchitic and various sub-infammatory attacks, its employment has ofter. helped on a fatal termination. No practitioner can have had much experience without repeatedly seeing, how very badly many patients bear even the smallest dose of calomel, and how poisonous its effects are in some examples; nor without learning how desirable it is to be cautious in its exhibition, where we do not see its use clearly demanded, and where we do not know the peculiarities of a patient's constitution.

I am, Sir,

Your obedient servant, SENIOR. 